\title{
Implementing Operations Strategy: How Vertical and Horizontal Coordination Interact
}

Fabian J. Sting, Rotterdam School of Management

Christoph H. Loch, Cambridge Judge Business School

Forthcoming, Production and Operations Management 2016

\begin{abstract}
We study the implementation of operations strategy at six German manufacturers in mature businesses. Search theory argues that vertical coordination (i.e., unilateral top-down adjustment of lower-level search actions) balances stability against the improvement potential enabled by frontline search and also that horizontal coordination (i.e., bilateral adjustment among lower-level search actions) is required to ensure compatibility among the initiatives generated in various organizational subunits. Much less is known about how vertical and horizontal coordination interact in operations strategy implementation - that is the focus of this paper. We first study how horizontal and vertical coordination affect the compatibility and creativity of distributed search, triangulating our cross-level interviews with data on the manufacturers' productivity gains and their strategic projects. We then examine whether and how vertical and horizontal coordination interact. Our case comparisons suggest that leaving either one of them "loose" and keeping the other one "tight" results in a useful balance between compatibility and creativity; in contrast, tightening both types of coordination suppresses creativity and loosening both types risks incompatibility of initiatives across units. These results lead to a theoretical framework that identifies vertical and horizontal coordination as partial substitutes for operations strategy implementation.
\end{abstract}




\section{Introduction}

The overarching purpose of operations strategy is to integrate the process capabilities and activities of an organization with its business strategy while improving the ability of the operations system to facilitate that strategy (Hayes and Wheelwright 1984, Burgelman et al. 2008, de Meyer and Loch 2008). In order to support business strategy, operations strategy employs a portfolio of projects: multiple technology and process development initiatives proceed in parallel. Such a portfolio is complex because its constituent projects interact in nonsimple ways - if not because of technical compatibility (Chao and Kavadias 2008, Kim et al. 2014) then for economic reasons such as limited budgets (Noda and Bower 1996). Given this complexity, there is rarely one single person who understands all the decisions; hence the organization must distribute decisions and innovative initiatives across multiple actors, each with only partial knowledge (Loch and Terwiesch 2008). For this reason, operations strategy implementation cannot be characterized as straightforwardly executing the directives suggested by some global optimization program; it should rather be recognized as a process involving search (March and Simon 1958, Cyert and March 1963, Levinthal 1997, Loch and Kavadias 2011), in which explorations by boundedly rational actors are combined to yield performance improvements that may involve new technologies, new practices, or new skills.

This distributed search for improvements and significant innovations requires integrating the activities and solution proposals of many distributed organizational actors (Loch and Tapper 2002). With regard to implementing strategy in general, scholars (e.g., Burgelman 1983, Noda and Bower 1996) have identified two simultaneous processes. First, the top-down inductive process cascades the strategic intent of the business strategy into more fine-grained subgoals for the development of technological capabilities. Stability is thereby fostered as lower-level actors (ideally) align their own decisions with the overarching directive of the business strategy (Wheelwright and Clark 1992). This inductive process is often facilitated by "strategy cascading tools"- such as key performance indicator (KPI) systems, portfolio selection aids (Cooper et al. 1998), and scorecards (Kaplan and Norton 1996). Second, the bottom-up autonomous process invites undirected innovation impulses from frontline actors to adapt and refine the existing 
operations system. This process draws from the opportunities that emerge from significant new technologies as well as from the tinkering or experimentation of frontline actors in their domains. To ensure both stability and innovation, strategy implementation should strike a balance between top-down and bottom-up elements (Burgelman and Grove 2007, Hutchison-Krupat and Kavadias 2014, Chandrasekaran et al. 2015).

Previous work has characterized vertical coordination (i.e., unilateral top-down adjustment of lower-level search actions) and coexistence of top-down and bottom-up processes (Kim et al. 2014). The literature has also pointed out the need for horizontal coordination (i.e., bilateral adjustment among lowerlevel search actions) to ensure that the distributed searches undertaken by different organizational units do not compromise one another (Mihm et al. 2003). This seems particularly critical for autonomous bottomup processes. However, an important lacuna remains in our understanding of the interactions between vertical and horizontal coordination. Theoretical representations of horizontal and vertical coordination exist in formal search theory (Levinthal 1997, Mihm et al. 2010), and empirical studies of both vertical (Maruchek et al. 1990) and horizontal (Gokpinar et al. 2010) coordination have been carried out. However, there has been no empirical investigation to date that addresses the interaction of vertical and horizontal coordination. Using agent-based simulations, Rivkin and Siggelkow (2003) propose that vertical and horizontal coordination are complements. However, this proposition is based on a rudimentary representation of the two dimensions of coordination, and so of their interaction: horizontal coordination is reduced to firm-wide incentives for lower-level managers, and vertical coordination is reduced to a top manager's veto rights.

Realistic interactions between vertical and horizontal coordination may be much richer. In order to characterize these, we conducted in-depth case studies using six manufacturing plants in mature industries as units of analysis. We studied how vertical and horizontal coordination were used in operations strategy implementation and also how they influenced each other. We triangulated our theory building by examining the manufacturers' strategic projects and their productivity improvement performances. We found evidence for subtle interactions between vertical and horizontal coordination. In the context of tight 
vertical coordination (intense unilateral top-down adjustment of distributed search), loose horizontal coordination leaves search initiatives the freedom for small, autonomous experiments (albeit under topdown guidance) that are unimpaired by the needs of other units; these circumstances foster creativity. Thus, loose horizontal coordination can cushion vertical coordination's trade-off between compatibility and creativity. In the context of tight horizontal coordination (with strong compatibility needs), loose vertical coordination leaves distributed search initiatives room to widen their search domains and "stay out of each other's hair"; hence they can avoid freezing up because of compatibility concerns. Thus, loose vertical coordination can cushion horizontal coordination's trade-off between compatibility and creativity. Vertical and horizontal coordination therefore emerge as partial substitutes, so tightening one of them helps to balance compatibility and creativity. However, tightening both suppresses creativity and loosening both risks inconsistency across distributed activities. These findings extend search theory, and they offer useful guidance for the implementation of operations strategy.

\section{Theory: Strategy Implementation as Vertical and Horizontal Coordination}

Strategy implementation involves both vertical and horizontal coordination. If all decisions were coordinated top-down by a central unit then horizontal coordination would be implied; however, implementing strategy requires that top-down and bottom-up processes be balanced in order to achieve both stability and the problem-solving creativity of distributed search (Burgelman 1983, Rotemberg and Saloner 2000, Burgelman and Grove 2007). Although the balance may shift from bottom-up toward topdown processes as an organization matures (Gavetti and Rivkin 2007), both processes continue to coexist in the manufacturing organizations of even mature industries (Kim et al. 2014).

Horizontal coordination is necessary because the numerous improvement initiatives of organizational subunits form a "project portfolio" (Roussel et al. 1991, Wheelwright and Clark 1992, Cooper et al. 1998, Loch and Kavadias 2002) and the initiatives in this portfolio necessarily interact with each other (Anderson and Joglekar 2005, Chao and Kavadias 2008). There is an abundance of literature analyzing the portfolio problem at tactical and operational levels-using mixed-integer programming 
frameworks to elaborate on "in" and "out" decisions under conditions of constrained resources (Kavadias and Chao 2008). However, this operational optimization approach is plagued by limiting (tractability) assumptions as well as by a lack of robustness and transparency; hence it is not widely accepted in business practice and has had little impact on research at the strategic level (Loch et al. 2001, Shane and Ulrich 2004). Kavadias and Chao observe that significantly less work has been done at this level, and most of it is based on single case studies that aim to develop best practices for shaping a strategic portfolio.

Search theory views strategy implementation as organizational problem solving and therefore takes complexity - that is, nontrivial interactions among numerous initiatives — as its starting point (Simon 1962, Levinthal 1997). Because complexity makes it impossible to determine a priori the right course of action and then "align" the organization, boundedly rational individuals search for alternatives in the neighborhood of already known solutions, sequentially evaluate alternatives, and terminate search efforts once they have identified a solution that is acceptable. Search scholars have shed light on how organizations adapt to and perform on fitness landscapes of varying complexity, or how an organization's strategy evolves as it learns more about its complex environments (Levinthal 1997, Kavadias and Sommer 2009). Search theory has also examined how organizational search dynamics interact with formal and informal organizational structures (Mihm et al. 2003, Gulati and Puranam 2009). Two qualitative results from search are relevant to our study.

1. Vertical coordination. In line with the strategy process literature, Mihm et al. (2010) and Sting et al. 2011) demonstrate how top-down adjustment fosters stable improvement performance at the cost of losing bottom-up search creativity. Moreover, vertical coordination alone may not eliminate the risk of incompatible distributed search because of limited processing power and a lack of detail knowledge at the top level (Rivkin and Siggelkow 2003, Sting et al. 2011).

2. Horizontal coordination. Siggelkow and Rivkin (2005) argue that increased bottom-up exploration can diminish performance when the domains of frontline managers are interdependent because the separately generated initiatives may cause incompatibilities. Gokpinar et al. (2010) 
provide empirical evidence that a lack of horizontal coordination reduces outcome quality.

So search - by exhibiting the trade-offs that emerge from vertical and horizontal coordination-provides a useful framework for our research question. Table 1 summarizes the above predictions from this framework when not incorporating interdependencies; that is, it represents the state of search theory by assembling the isolated effects of vertical and horizontal coordination on distributed search for each cell.

Table 1: Naïve Theory of Vertical and Horizontal Coordination

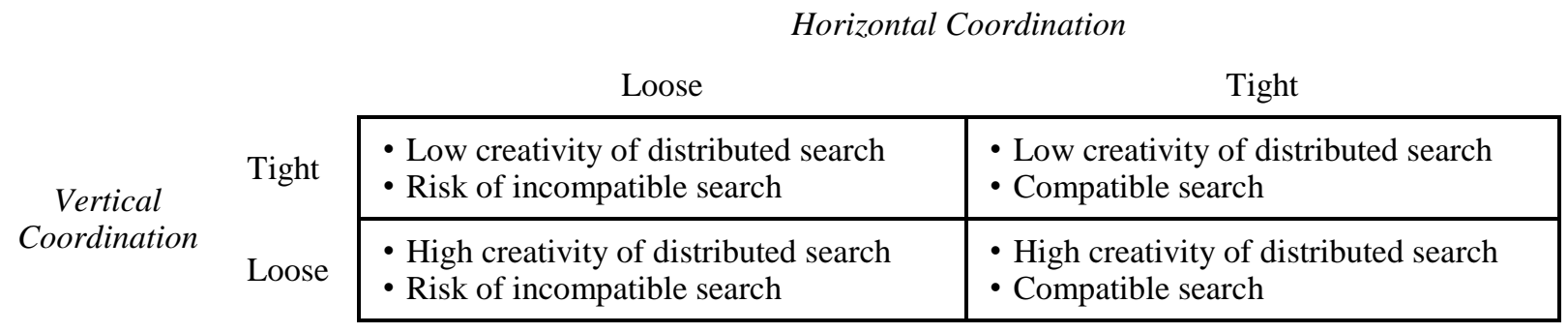

One agent-based simulation (Rivkin and Siggelkow 2003) does examine a specific interdependence between vertical interventions (a "vetoing vs. rubber-stamping CEO") and horizontal alignment ("firmwide vs. parochial incentives"). This work concludes that "an active vertical hierarchy" (the vetoing CEO) can be more valuable when frontline managers' adhere to firm-wide incentives - in other words, they conclude that vertical and horizontal coordination are strategic complements. However, this model does not address horizontal coordination in the broad and dynamic sense of the current study; it considers only static ex-ante alignment but not incompatibility of decentralized actions (which is "edited out" by the CEO who assembles partial proposals into an overarching change). In particular, lower-level managers adjust to one another via dynamic mechanisms such as real-time collaboration and negotiation (Galbraith 1974). It is simply unanswered by existing theory whether (and if so, how) horizontal coordination affects the trade-off between stability and creativity that vertical coordination establishes. To address this question we take an inductive, case study approach and explore whether and how vertical and horizontal coordination interact. In doing so, we aim at building theory for each cell of Table 1. 


\section{Case Method and Data}

\subsection{Case Selection}

We theoretically sampled (Yin 2009, p. 53) six German manufacturing units from diverse, mature manufacturing industries with a proven record of process mastery - that is, efficient production processes were in place. We selected only units that shaped their own operations strategy and that had a top management team with a minimum of four years of tenure. As a basis for our theoretical sampling, we used data gathered in the screening process of INSEAD's European-wide Industrial Excellence Award (IEA), for which all six manufacturers were finalists between 2006 and 2008. Even though commonalities in geography and process mastery minimize any variance due to cultural differences or instable process, the diversity of these manufacturing industries preserves some variation. Moreover, our initial theoretical sampling plan stipulated the inclusion of two units (CONTROLLERS, GLASS) with "centralized" and two units (AUTO, MEDICAL) with "decentralized" decision making structures; this preliminary assessment of these characteristics was based on previous impressions from plant audits. In the course of our research, we reviewed and refined the sampling plan (cf. Eisenhardt 1989, Yin 2009) and added two organizations (DRIVES, FITTINGS) to allow for more variation in size (as measured by number of employees) and in vertical coordination. We stopped adding cases as "theoretical saturation" (Eisenhardt 1989) was approached. We explained the research project to each organization's top management and made it clear that our follow-up visit was no longer in the context of a competition. Each of the six organizations we contacted agreed to participate. Data from the same six manufacturers are also used by Kim et al. (2014) to focus on how (top-down or bottom-up) strategic projects are formed. To study how vertical and horizontal coordination interact, we use additional data on vertical and horizontal coordination mechanisms as well as on distributed search performance.

\subsection{Data Collection and Research Methods}

We collected data using multiple data collection methods, by both authors visiting the organizations together, and by combining quantitative and qualitative data (Jick 1979, Eisenhardt 1989, Yin 2009). The 
four data sources we used are described next.

[1] Evaluation questionnaires. These were completed by the companies and submitted by top management in the context of the IEA between 2006 and 2008. The questionnaire responses included organization charts, factory layouts, and supply chain maps; they also described operational performance in manufacturing, delivery, new product and process development, service delivery, and human resources management. The performance indicators measured operational efficiency in terms of product and process quality, cost performance, and flexibility. Missing performance indicators were updated during our visits for the last two years before 2009 so that improvement rates could be calculated.

[2] Reports from the IEA evaluation visit. All IEA finalists (and thus all participants in this study) received a one-day evaluation visit, between 2006 and 2008, from an evaluator team that included both authors. The team verified the questionnaire data and added qualitative and unfiltered impressions from the shop floor by speaking with frontline personnel and the workers' council. ${ }^{1}$ It summarized each organization's process mastery, structure and decision-making process. These data (i.e., sources [1] and [2]) were available before our study and supported case selection as well as productivity developments.

[3] Multilevel interviews. Both authors spent a second day conducting interviews on-site at each selected organization in the first half of 2009. (Auto had already been visited, as a pilot case, in November 2008 and received a third visit in May 2009 to obtain data in accordance with the revised protocol.) Each firm was asked to arrange meetings with individuals representing top management, middle management, frontline management, and frontline workers. Interviews were semistructured, featured a level-specific questionnaire, and lasted about 90 minutes. We had knowledge of each organization's formal structures, major functions, and manufacturing processes, and we asked the firms to provide access to interviewees such that all key areas would be covered. Each organization comprised more than three managerial levels, so we schematically divided the organizations into three layers: top, middle, and frontline management. Top management refers to the unit head (this was the CEO in one case, the division manager in two cases,

1 The workers' council is an institution, established by the German workers' co-determination act, which represents workers' issues to management. Workers' council comments are a useful source for cross-checking management statements. No conflicts or inconsistencies between management and workers' council statements were observed in our host organizations. 
and functional heads in three cases) and that person's "reports" or immediate subordinates. Frontline management is the lowest level with staff responsibility, and middle management refers to managerial positions in between. Table 2 summarizes the number of interviews per organization. For key functions we arranged interviews with individuals from all three managerial layers. At the top management level we conducted individual interviews to avoid retrospective biases. At the middle and frontline management levels and with workers, we conducted group interviews with four to six individuals; for these we ensured that each group's members had the same organizational rank (to preclude self-censoring in the presence of superiors). Each participant was given an equal chance to speak openly; when time ran short, groups were split up to make sure that all important topics were covered.

Table 2: Informants in the Case Study Organizations

\begin{tabular}{lcccccc}
\hline Organization & $\begin{array}{c}\text { Top } \\
\text { management }\end{array}$ & $\begin{array}{c}\text { Middle } \\
\text { management }\end{array}$ & $\begin{array}{c}\text { Frontline } \\
\text { management }\end{array}$ & $\begin{array}{c}\text { Frontline } \\
\text { workers }\end{array}$ & $\begin{array}{c}\text { Number of } \\
\text { employees }\end{array}$ & $\begin{array}{c}\text { Decision making } \\
\text { structure" }\end{array}$ \\
\hline AUTO & 4 & 4 & 7 & 13 & 2,500 & decentralized \\
CONTROLLERS & 2 & 4 & 2 & 6 & 700 & centralized \\
MEDICAL & 2 & 6 & 4 & 6 & 800 & decentralized \\
DRIVES & 2 & 3 & 3 & 9 & 2,400 & decentralized \\
GLASS & 5 & 4 & 3 & 6 & 1,000 & centralized \\
FITTINGS & 1 & 3 & 2 & 6 & 530 & centralized \\
\hline
\end{tabular}

[4] Database of strategic projects. From each organization, we obtained a list of current (ongoing) strategic projects, including all projects with budgets that were formally tracked by top management as the "unit's strategic projects". These projects embodied the unit's current high-priority actions. Interviewees were asked about each projects' contents, goals, and origin. We were able to unequivocally locate all 111 projects' origins (from the top, or middle and frontline levels of the organization). Our units of analysis are the six cases (where Kim et al. (2014) focus their analysis on the top-down or bottom-up formation of the 111 strategic projects, referring to them as "action plans"). Data collection and research method are summarized in Table 3, which is adapted from Cardinal et al. (2004). 
Table 3: Detailed Research Methods for Case Analyses

\section{Selection of cases from INSEAD's IEA finalists}

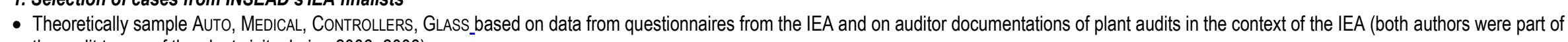
the audit teams of the plant visits during 2006-2008).

- Identify the top-level informants (e.g., the unit head of every site of the four manufacturers) from the IEA documentation.

- Contact and schedule site visits and interviews at top management, middle management and frontline level at Auto (Nov. 2008), CONTROLLERS (Jan. 2009), MEDICAL (Feb. 2009), and GLASS (Mar. 2009).

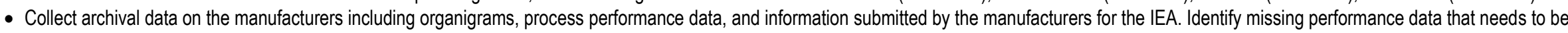
updated during the site visits (i.e., data for 2008).

\section{Site visit preparation}

- Develop three different interview protocols—based on the search literature-for different levels: the top management, middle management, and frontline levels (all protocols are written in German).

- Revise interview protocols after the pilot case visit at Auto to enhance clarity.

- Modify interview protocols after the visit at CONTROLLERS (which maintains a portfolio of strategic projects) to include questions on strategic projects, their origin and content, and the individuals involved.

3. Site visits

- Two researchers (the authors) conduct interviews (in German) with multiple informants (e.g., unit head, middle managers, frontline managers and workers) separately to avoid retrospective bias and selfcensoring.

- Establish and verify origins (top-down vs. bottom-up) and content categorizations (manufacturing process improvement or not) of each manufacturers' strategic projects during the site visit; verify available (from the IEA) process improvement data and its contributors.

- Follow-up visits at AUTO in May 2009 to gather additional data on strategic projects (systematic questions on origin and content of strategic projects were added to the protocols after the visit to CONTROLLERS in Jan. 2009).

- Collect other forms of data-for example, documentation on strategy implementation tools (e.g., balanced scorecards and KPI systems), on the strategy implementation process, and on strategy implementation meetings.

- Researchers immediately discuss and share insights after each interview.

- Transcribe the interviews and other forms of data (in German) within 24 hours of the visit. Contact informants for clarification as needed.

4. Data analysis

- Create tables summarizing the evolution of strategic projects (columns) and the involvement of organizational actors across hierarchy levels (rows).

- Both researchers produce (jointly, iteratively) summarizing case write-ups, in English, for each manufacturer's strategy implementation.

- Both researchers (independently) use interview transcripts to produce lists for observations indicative of (loose) vertical coordination in each case.

- Merge both researchers' lists of observations on vertical coordination; remove those items with for which no concrete evidence was available in the context of strategic projects.

- Juxtapose case write-ups with strategic projects. The interdependencies of bottom-up projects with other subunits suggested the relevance of horizontal coordination.

- Both researchers (independently) use interview transcripts to generate lists of observed horizontal coordination mechanisms.

- Merge the researchers' lists of horizontal coordination; remove those items with for which no concrete evidence was available in the context of strategic projects

\section{Additional sampling}

- Select DRIVES and FITTINGS as additional cases to provide more variation on size and vertical coordination characteristics.

- Contact and schedule site visits (in analogy to step 1) at DRIVES (Apr. 2009) and FITTINGS (May 2009); include them in the cross-case analysis and in the within-case analysis.

6. Theory development

- Analyze interview data for evidence of vertical and horizontal coordination and their interaction. Juxtapose analysis with quantitative data on strategic projects and improvement performances.

- Develop higher-level findings by juxtaposing the main constructs and their interaction with those in search theory.

- Share and discuss insights from cases with the top management teams of all six manufacturers in written form and via presentations. Rule out rival explanations (from practice and theory). 
Consistent with the case study approach, we modified the design of our research during its course. Most importantly, after visiting CONTROLLERS (and obtaining their list of strategic projects) as the second case we decided to collect data on the strategic projects of each manufacturer and so revised our multilevel interviews protocol accordingly for all subsequent site visits. We thus also spent a third day at AUTO to obtain information about their strategic projects. To develop theory we analyzed the interview data for vertical and horizontal coordination and their influence on distributed search, and sought to triangulate evidence by examining quantitative data on the manufacturers' strategic projects and their improvement performances. We then examined the data across cases for evidence on the interaction of vertical and horizontal interaction. To strengthen our theory building on the interaction between vertical and horizontal coordination, we juxtaposed the constructs and their interactions to the corresponding constructs and interactions proposed by search theory. In order to identify and rule out rival explanations, we presented and discussed the process and the results of this study to the top management of all six organizations.

\section{Case Analysis}

\subsection{The Manufacturing Organizations}

AUTO manufactures rear and front axles, axle gearboxes, axle carriers, and shaft drives-key components of the chassis. Production processes include metalwork (casting, welding, and cutting) and assembly. AUTO's top management channels organizational search by setting broad strategic directions. The unit head likes to spark creativity by delegating the search for strategic projects: "We need ideas from everywhere in the plant." For implementing top-level goals, middle and frontline levels can define their actions independently. Both at the middle and frontline levels, institutionalized and powerful steering committees enforce horizontal coordination of actions. Moreover, cross-functional weekly meetings give middle managers the opportunity to discuss their projects and to clarify the ramifications of those projects outside their own departments and on unit goals; peer sanctions are used to punish uncooperative behavior.

CONTROLLERS develops and supplies customized power controllers for industrial automation, primarily for machinery and tool industries. Key production processes at CONTROLLERS are product 
engineering, assembly of printed circuit boards and cabinets, and testing. The unit head and his CFO are the "gravity center" of search activities. The unit head takes ownership of strategic projects that tackle new business opportunities, personally negotiating with potential new customers. He typically initiates the discussion by handing out a detailed proposal that already includes a specific course of action for reaching those goals. Middle managers (two business segment heads plus functional heads) are personally held responsible by the division head to "fill top-level strategic projects with life and execute" and - if the road map formulated by the head leaves space for interpretation-to propose their own projects. Horizontal coordination among middle managers occurs mostly on a "case-by-case" basis. CONTROLLERS' middle managers have significant lateral autonomy. Moreover, although middle managers share an expectation of cross-unit collaboration, objectives and rewards vary considerably among subunits.

MEDICAL develops and manufactures medical devices for emergency, home-care, and diagnostics applications - in particular, devices for breathing support and defibrillation. All of MEDICAL's diverse manufacturing activities can be classified as assembly processes followed by detailed functional testing. The top management team annually sets sales and profitability targets. Apart from these corporate goals and their immediate financial subgoals (e.g., sales and profitability goals for specific business segments), top management is not involved in forming or implementing projects. Rather, it mostly sets constraints while middle managers directly engage in search and in initiating projects related to strategic changes in product and process configurations. Empowerment of MEDICAL's frontline employees is noteworthy. For example, each manufacturing team has developed its own KPI system for measuring performance. Frontline employees initiate improvements, which process engineers cannot turn down without the initiating employee's consent. Horizontal adjustment of distributed initiatives, however, occurs sporadically. Coordination mechanisms are institutionalized only via cross-functional scorecards mostly at the top level, whereas middle and frontline managers "play required horizontal adjustments for process changes by ear".

DRIVES manufactures pneumatic and electric drives for factory automation applications in various industries. Key manufacturing processes are extrusion of plastic parts, metal forming (tubes), and final 
drive assembly. The top management team's search activities focus on setting priorities and standards. Of most importance is that top management decided to assign delivery reliability the highest priority for all its activities - even though corporate policy required a cost focus. Search activities at lower levels are not restricted by the top: as a general principle, the top management team of DRIVES does not push content decisions down the organizational hierarchy; instead it pursues an "all content is delegated" approach. In particular, the priority shift from cost to delivery speed and reliability resulted from a bottom-up project. DRIVES has rigorous and detailed standards that assure for horizontal coordination across middle and frontline levels of the unit. The management team acts as a guardian for standardized problem-solving and decision-making with horizontal adjustments. Requirements for horizontal coordination are high: managers at all levels must pass their initiatives through institutionalized clearing rounds with their peers. Shared objectives, rewards, and a collaborative culture pervade top, middle, and frontline levels.

GLASS develops, produces, and sells specialty glass tubes for applications in pharmaceutical, electronics, and environmental industries. The manufacturing process consists of glass melting, extrusion, and cutting. GLASS's top management team is actively engaged in seeking out and formulating strategic projects. The division manager subsequently assigns execution of strategic projects to middle management. For this task, middle managers' allowance for distributed decision making must be earned by a track record: once process teams have gained top management trust, they may contribute their own ideas on how to achieve top-level goals. For underperforming process teams, the KPI cockpits are specified with goals and means by top management to "better push them into action." Horizontal coordination between distributed search activities occurs via cross-functional process teams, each led by one process head. Each team supervises the entire process from inbound logistics to manufacturing, selling, and distributing one of the four product lines. Middle managers share a common set of objectives and rewards.

FITTINGS manufactures medium and premium brass faucets. Its key processes are metalworking (casting, chipping and cutting, galvanizing, and polishing) and assembly. The unit head of FITTINGS is the key actor in creating strategic projects for achieving the financial goals set by corporate management. Supported by a "plant dashboard" - a real-time information system that maintains KPIs and 
responsibilities - top management typically "breaks actions down" to the team level on the shop floor. Top management's specifies concrete actions to develop new manufacturing technologies, but they also target improving day-to-day process activities. For instance, the plant manager himself initiated and led the installation of "pull" lines in the assembly area. Middle and frontline management execute decisions from the top, all modifications require top approval. Horizontal coordination among FITTINGS's (less pronounced but existing) distributed initiatives is supported by transparency, shared process objectives, and the expectation that the unit head regularly intervenes to ensure compatibility for distributed search. Top management holds daily briefings with line managers and weekly reviews of shop-floor KPIs; these serve as the bases for making decisions on interdependent production processes.

\subsection{Vertical Coordination of Organizational Search}

The previous case descriptions illustrate that each organization relies to some extent on both an induced strategy process (top-down implementation) and an autonomous strategy process (bottom-up implementation) in carrying out its operations strategy. The top-down character of organizational search includes two dimensions: the extent to which middle- and lower-level search decisions are unilaterally adjusted via vertical coordination (the vertical arrow in Figure 1), and the extent to which actual search decisions are centralized at the top management level.

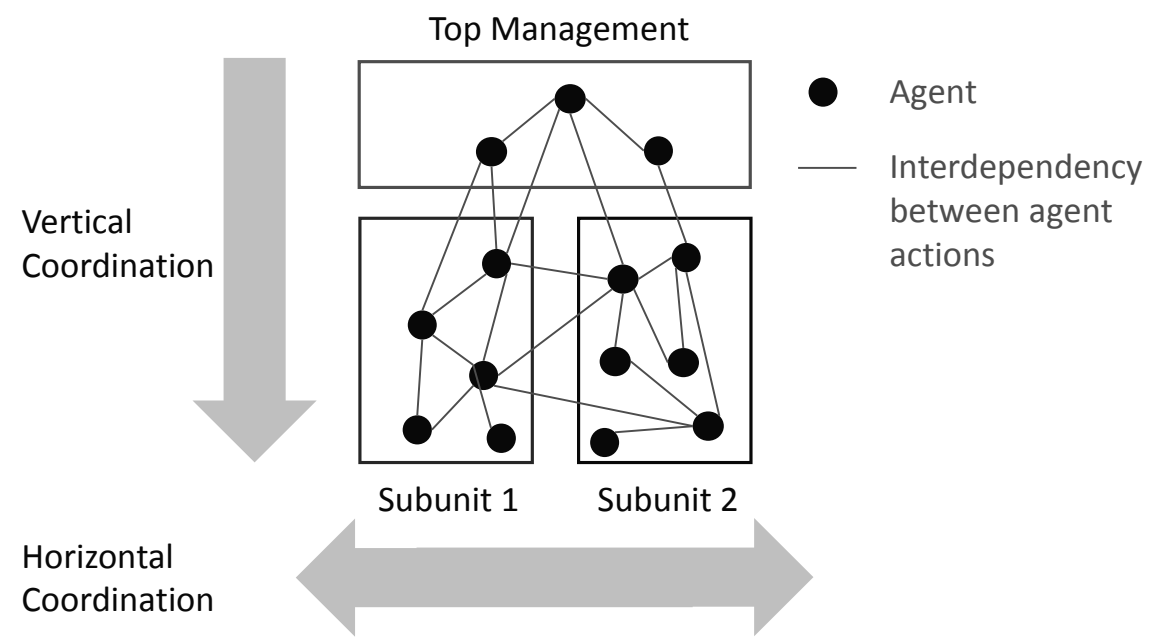

Figure 1: Organizational Search and Its Horizontal and Vertical Coordination 
In this study we focus on vertical coordination, however, the latter dimension also varies among the manufacturers. For instance, many detailed decisions related to novel smelting technology are made by the top management at GLASS whereas MEDICAL's top management refrains completely from instituting or even influencing detailed search. Our cases thus add nuance to stylized models of search by revealing that interdependent search activities are pursued by top management and lower-level employees working in parallel, as illustrated schematically by the agent "nodes" in Figure 1. The parallel search initiatives interact (they may support or hinder one another) and so horizontal coordination may be required to prevent incompatibilities; this function is represented by the horizontal arrow in Figure 1. The vertical and horizontal coordination constructs adopted by formal search models are too stylized to capture observations in the manufacturing cases. So before we describe how vertical and horizontal integration interact, we analyze each firm's search processes in terms of their coordination mechanisms.

With regard to vertical coordination, it turns out that there are substantial differences among the cases. For instance, when the unit head of Controllers himself explored new technologies and product modifications for novel uses, he specified detailed action plans for execution by lower-level actors; he also involved himself in the implementation of these initiatives. Such behavior is in stark contrast to Drives, where the unit head refrained from specifying action plans and, more generally, from implementing initiatives. We accumulated the individual researchers' observations from the interview protocols that characterize (loose) vertical coordination at each manufacturer (and removed those for which no concrete evidence was given in the context of strategic projects); all the cases are described in Table 4. The table assesses vertical coordination by listing ways in which lower-level subunits can be exempt from strict topdown adherence of their search decisions. Thus a high density of "Yes" entries indicates loose vertical coordination.

MEDICAL is the organization with the loosest vertical coordination of organizational search. Here, top management commonly "rubber-stamps" initiatives by lower organizational levels because the unit head is convinced that "they know much better, and should tell us what we should do." Top-level goals are determined and constantly refined by lower-level initiatives, and even financial goals "are formed on the basis of the initiatives that they propose." Similarly, MEDICAL's middle managers allow frontline units to 
form their own initiatives - for instance, devising their own KPIs and allocating budgets to shape their own strategic projects.

Table 4: Observed Vertical Coordination by Organization

\begin{tabular}{|c|c|c|c|c|c|c|}
\hline Observation & MEDICAL & DRIVES & Auto & CONTR. & FITTINGS & GLASS \\
\hline $\begin{array}{l}\text { Actions for implementing top goals are usually } \\
\text { chosen by middle level }\end{array}$ & Yes & Yes & Yes & Yes & Yes & No \\
\hline Strategic projects can emerge from frontline level & Yes & No & Yes & Yes & No & No \\
\hline $\begin{array}{l}\text { Top management refrains from implementing } \\
\text { strategic goals }\end{array}$ & Yes & Yes & Yes & No & No & No \\
\hline $\begin{array}{l}\text { Middle managers usually make "first proposals" to } \\
\text { form goals }\end{array}$ & Yes & Yes & Yes & No & No & No \\
\hline Top-level goals can be altered by middle level & Yes & Yes & Yes & No & No & No \\
\hline $\begin{array}{l}\text { Actions for implementing middle goals are usually } \\
\text { chosen by front line }\end{array}$ & Yes & Yes & No & No & No & No \\
\hline $\begin{array}{l}\text { Top management expects to adopt "initiatives from } \\
\text { below" when forming strategy }\end{array}$ & Yes & Yes & No & No & No & No \\
\hline Top-level goals are derived from middle-level goals & Yes & Yes & No & No & No & No \\
\hline
\end{tabular}

In stark contrast is the tight vertical coordination at GLASS, where lower-level search decisions are adjusted to top-level wishes without much leeway. Here multiple vertical coordination mechanisms ensure that lower-level decisions match up well with the desires of top management. For example, the general manager of GLASS himself specified detailed actions (for capacity shifts and expansions) that middle managers had to follow, and their unit goals were also unilaterally defined by top management. Moreover, neither top management nor middle management considered the possibility that frontline management levels could contribute strategic projects. Although it is not straightforward to quantify a manufacturer's "degree of vertical coordination" on a measurable scale, Table 4 characterizes the relative intensity of vertical coordination among the manufacturers in our case sample.

Effect of vertical coordination on organizational search. Vertical coordination of search is used by these manufacturers to align operational actions with the goals defined on a higher management level; in the words of FITTINGS's unit head, "there must be a consistent cascade of higher-level goals and specific lower actions that directly support these goals." Vertical coordination thus exemplifies traditional top-down models of operations strategy formation and implementation (Kim et al. 2014). Lower-level decisions are adjusted to support unifying goals or strategic priorities formulated at higher levels of the 
manufacturing organization. For instance, GLASS's top-level initiative to expand capacity was implemented top-down in the distinct smelting and extrusion areas where new processes were developed. The overall goal of capacity expansion was translated by top management into lower-level actions (e.g., specifying the technology and capacity of a new glass reactor), and compatibility between the smelting and extrusion manufacturing processes was ensured by top-down specified actions.

At the same time, vertical coordination confines the breadth of lower-level search. As lower-level actions must adhere more tightly to top-level goals, there is less room for experimentation and search. The unit head of FITTINGS commented: "The action plans define concrete areas for improvement. That is how we mobilized the organization to implement a pull-system throughout the plant." A production line head from FitTINGS confirms this focus: "Most of us just execute to meet the goals; they are quite specific."

To triangulate these findings, Figure 2 charts each organization's portfolio of strategic projects (i.e., those initiatives that were monitored directly by the unit head and his direct reports) in terms of their origins - that is, from top management or lower levels. A strategic project originating at a particular organizational level reflects search activities undertaken at that level (even though it is top management that determines which initiatives, their origins notwithstanding, are "strategic"). The first observation from this analysis is that the organizations that use a relatively intense vertical coordination of search (Table 4: FITTINGS and GLASS) also have the largest shares of strategic projects initiated at the top level (Figure 2). Conversely, organizations with the loosest vertical coordination (MEDICAL and DRIVES) have the largest shares of projects that are initiated bottom-up. Furthermore, distributed search focuses on specific areas, hence Figure 2 distinguishes between strategic projects in general ("Overall") and the subset of strategic projects that addresses improvements to the manufacturing process ("Process"). This latter content of lower-level strategic projects dominates when considering all cases together. And, in each case study, middle or frontline levels contribute a larger share to process projects than to strategic projects overall. Even for CONTROLLERS, where search is initiated in a top-down fashion and where detailed search decisions are made by the unit head (and so decisions are fairly centralized), six of the ten strategic projects that involved the manufacturing process come from middle or frontline levels. The CONTROLLERS unit head commented that "the more strategic the topic of interest is, the more content comes from my 
side. But not all manufacturing process initiatives should originate in my head." For a more detailed breakdown of the content of strategic projects see Tables 3 and 4 in Kim et al. (2014).

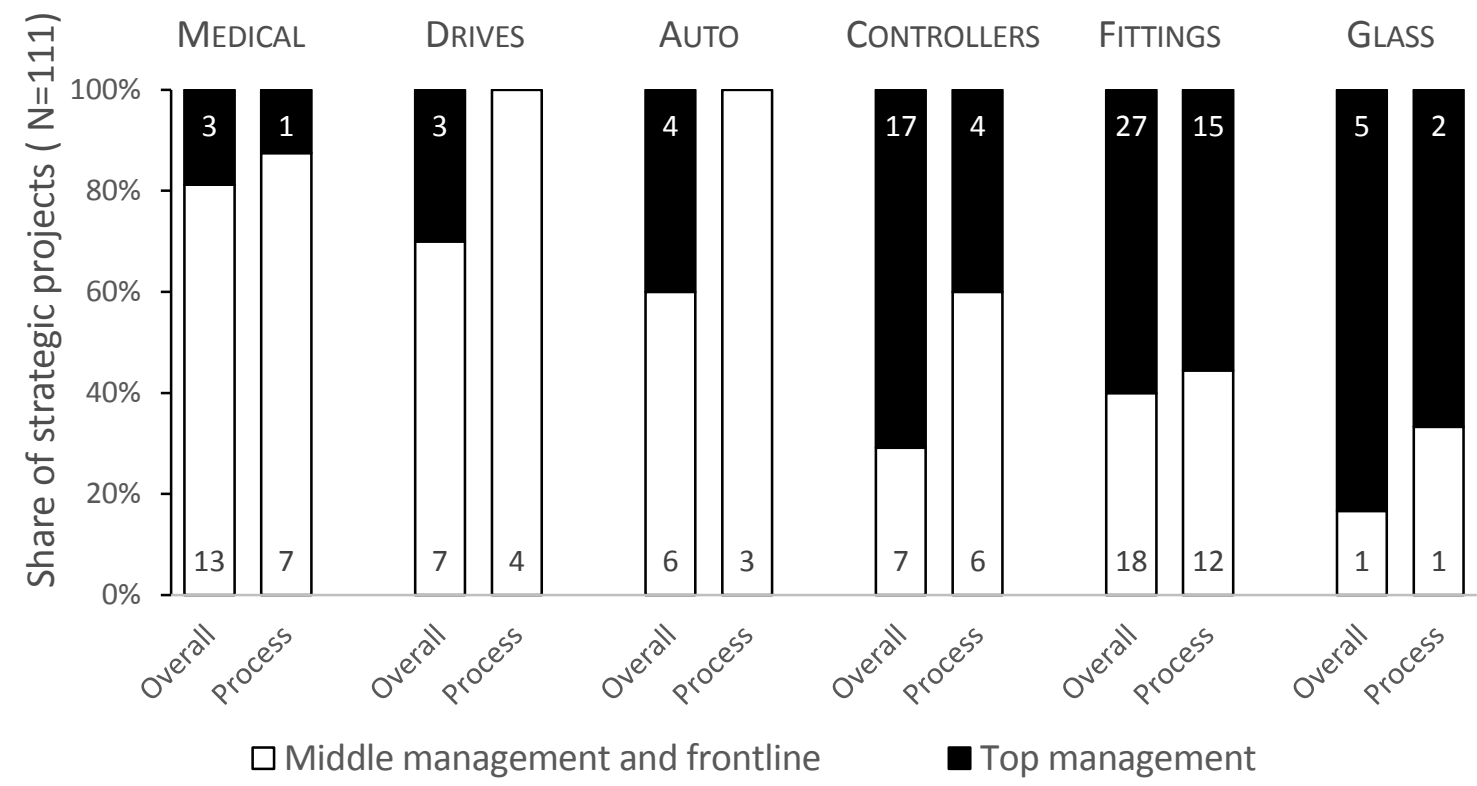

Figure 2: Strategic Projects by Origin and Manufacturing Organization

\subsection{Horizontal Coordination of Organizational Search}

It is common for bottom-up strategic projects to interact with decisions made in other subunits. For example, DRIVE's bottom-up initiative on plant segmentation — which shifted the unit's focus from cost to speed - required substantial changes in the inbound logistics department. Therefore, bilateral horizontal coordination is relevant for strategy implementation. The six manufacturers employed several types of coordination mechanisms, formal and informal.

- Structural coordination - matrix structures, liaisons, temporary project organizations, steering committees (e.g., a formal process organization at CONTROLLERS)

- Coordination standards - formalized horizontal problem solving (e.g., AUTO's production system), coordinating routines, and standardized protocols for decision and goal adjustment

- Incentives - shared objectives and measures; common rewards (e.g., overlapping scorecards and shared KPI cockpits at GLASS's middle level)

- Intervention - top management intervening in and prioritizing middle- and bottom-level actions on 
a regular basis (e.g., the weekly coordination sessions called by FITTINGS's unit head)

- Culture - the building of trust through establishing a track record of collaboration, expectations of transparency (e.g., DRIVES's motto that “selfish optimization will become obvious").

We accumulated the researchers' interview observations that characterized horizontal coordination mechanisms for each manufacturer (and removed those for which no concrete and consistent evidence was available on how they led to horizontal adjustment among strategic projects). See Table 5.

Table 5: Observed Horizontal Coordination Mechanisms by Organization

\begin{tabular}{|c|c|c|c|c|c|c|}
\hline & AUTO & DRIVES & FITTINGS & GLASS & CONTR. & MEDICAL \\
\hline $\begin{array}{l}\text { Cross-functional scorecards and KPI boards at top and } \\
\text { middle levels }\end{array}$ & Yes & Yes & Yes & Yes & Yes & Yes \\
\hline Formal matrix structure bridges functional areas & Yes & Yes & Yes & Yes & Yes & No \\
\hline $\begin{array}{l}\text { Expectation of transparency or collaboration at middle } \\
\text { level }\end{array}$ & Yes & Yes & Yes & Yes & Yes & No \\
\hline Process orientation evident at middle level & Yes & Yes & Yes & Yes & Yes & No \\
\hline Process orientation evident at frontline level & Yes & Yes & Yes & No & Yes & No \\
\hline Standards and routines for adjustment at middle level & Yes & Yes & Yes & Yes & No & No \\
\hline Horizontal adjustment at middle level in goal setting & Yes & Yes & Yes & Yes & No & No \\
\hline Shared measures and rewards at top and middle level & Yes & Yes & Yes & Yes & No & No \\
\hline $\begin{array}{l}\text { Expectation that top intervenes regularly to coordinate at } \\
\text { middle and bottom }\end{array}$ & No & No & Yes & No & No & No \\
\hline Standards and routines for adjustment at frontline level & Yes & Yes & No & No & No & No \\
\hline Horizontal adjustment at frontline level in goal setting & Yes & Yes & No & No & No & No \\
\hline Shared measures and rewards at frontline level & Yes & Yes & No & No & No & No \\
\hline Collaborative culture at front line level & Yes & Yes & No & No & No & No \\
\hline Adjustment by steering committees at middle level & Yes & No & No & No & No & No \\
\hline Adjustment by steering committees at frontline level & Yes & No & No & No & No & No \\
\hline
\end{tabular}

The mechanisms listed in the table are heterogeneous, yet calculating a "degree of horizontal coordination" would presume equal and additive contributions of coordination mechanisms. Nevertheless, the simultaneous existence (resp. absence) of numerous horizontal coordination mechanisms suggests that the manufacturer places strong (resp. weak) emphasis on horizontal coordination. Thus AUTO and DRIVES, which each feature multiple horizontal coordination mechanisms, can be said to have tight horizontal coordination; in contrast, CONTROLLERS and MEDICAL can be said to have loose horizontal coordination.

Effect of horizontal coordination on organizational search. Because of technological and manufacturing interdependencies, search initiatives undertaken in one organizational subunit usually affect 
initiatives or decisions in other subunits. Tight horizontal coordination encourages (and may even force) initiatives to account for their impact on the performance of other interdependent subunits, "with the intention to enhance our overarching goal achievements" (unit head of DRIVES). Increasing horizontal coordination - whether by formal means (e.g., structured horizontal iteration rounds at DRIVES) or by informal means (e.g., a process-oriented culture that bridges functional departments at AUTO)—improves the compatibility of distributed (and particularly of hitherto autonomous) search activities.

However, our interviews point to a second effect of horizontal coordination: constraining the breadth of distributed search. Search theory assumes that organizational actors can search in parallel; if incompatibilities arise during attempts to coordinate, then either someone must adapt or some initiative's solution proposal must be discarded. The organizations in our sample more actively constrain the decisions of a single actor, precluding some search at the outset and suppressing most iterative rounds of search before those activities would affect others. This type of influence was clearly evident at DRIVES, whose loose vertical coordination provided an environment supportive of frontline search activities. Even so, managers and workers were constantly aware of the need to adjust (horizontally, among interdependent departments) in "sometimes tedious rounds of iterations". Hence the frontline managers pursued and especially championed those initiatives they deemed to be already compatible (thus "not stepping on anyone's toes", as one production line head put it). Under these circumstances, search efforts that could have-after iteration and horizontal adjustment - contributed to improved organizational performance were never initiated in the first place because the adjustment aspect (which in this case aimed to improve production and delivery cycle times) was given priority over autonomous exploration. According to a middle manager at DRIVES: "This process of cross-functional shaking can be tedious and take more than three months to yield acceptable results across units. I believe this may also hinder innovation." Similarly, a functional head at AUTO remarked that "projects starting out by negotiating a common, process-based objective that solve all interdependencies across functions at once could be hampered in their creativity".

In contrast, a production managers at CONTROLLERS stated: "We act as entrepreneurs within our realms; and without giving much attention to neighboring sub-units and their decisions or requirements. So we can experiment and quickly implement solutions autonomously." At AUTO we observed that new 
creativity could be unleashed when employees were temporarily exposed to autonomous goals (and to temporarily relaxed horizontal coordination strictures) within an "aging production line" experiment. Although those workers considered only their own task performance without accounting for neighboring processes, that experiment yielded significant productivity and quality improvements (Loch et al. 2010).

That horizontal coordination reduces the breadth of distributed search is reflected also in manufacturing organizations' annual productivity improvements. The four organizations with more intense horizontal coordination (AUTO, DRIVES, GLASS, and FITTINGS) have the lowest annual productivity improvements (left panel of Figure 3) as well as the lowest share of frontline contribution to these improvements (right panel of Figure 3) in the case sample.
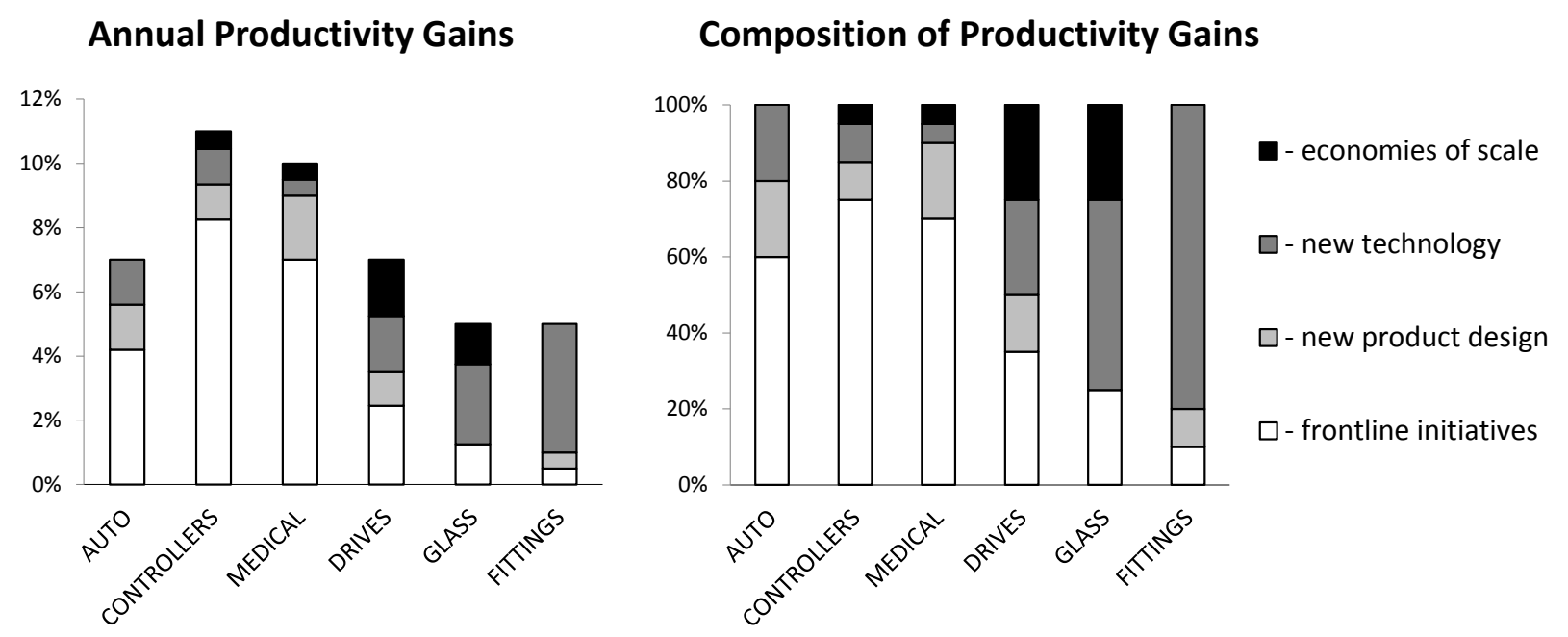

Figure 3: Productivity Improvement Performance by Organization

\subsection{Vertical and Horizontal Coordination}

We now turn to our core research question: How do vertical and horizontal coordination interact during the implementation of operations strategy? First, we observed that the six manufacturers employ combinations of vertical and horizontal coordination. We therefore undertake a cross-case analysis of whether and how the combined use of vertical and horizontal coordination affects both the compatibility and the breadth of distributed search activities. Table 6 summarizes the intensity of vertical and horizontal coordination (based on the observations reported in Tables 4 and 5) and also evaluates the impact and compatibility of distributed search while listing the evidence for that evaluation. The creativity of 
distributed search results from many middle and frontline employees contributing to improvement initiatives. As our study's design does not enable a direct measure of creativity, we use the impact of distributed search as a proxy by assessing the bottom-up contributions to productivity improvements and strategic projects.

We focus on the manufacturing process impact because our previous analysis (Figure 2) showed that, for all six cases, the manufacturing process is a common focus of distributed search. The compatibility of distributed search implies that aggregating the solutions from lower-level search yields an overall consistent configuration. We assessed compatibility by asking informants at all three levels about what conflicts between distributed strategic projects occur, and whether and how these conflicts were resolved. Incompatibility is indicated when there are unresolved conflicts across distributed strategic projects whose reconciliation would clearly benefit the manufacturing unit as a whole.

Table 6: Summary of Key Research Constructs

\begin{tabular}{|c|c|c|c|c|c|c|}
\hline & MEDICAL & DRIVES & AUTO & CONTR. & FITTINGS & GLASS \\
\hline Vertical coordination & Loose & Loose & Loose & Tight & Tight & Tight \\
\hline Horizontal coordination & Loose & Tight & Tight & Loose & Tight & Tight \\
\hline $\begin{array}{l}\text { Impact of distributed search } \\
\text { Annual productivity improvement } \\
\text { (\% bottom-up share) }\end{array}$ & $\begin{array}{l}\text { High } \\
10 \% \\
(70 \%)\end{array}$ & $\begin{array}{l}\text { High } \\
7 \% \\
(35 \%)\end{array}$ & $\begin{array}{l}\text { High } \\
7 \% \\
(60 \%)\end{array}$ & $\begin{array}{l}\text { High } \\
11 \% \\
(75 \%)\end{array}$ & $\begin{array}{l}\text { Low } \\
5 \% \\
(10 \%)\end{array}$ & $\begin{array}{l}\text { Low } \\
5 \% \\
(25 \%)\end{array}$ \\
\hline $\begin{array}{l}\text { Bottom-up strategic projects related } \\
\text { to the manufacturing process } \\
\text { (\% of all such projects) }\end{array}$ & $\begin{array}{c}7 \\
(88 \%)\end{array}$ & $\begin{array}{c}4 \\
(100 \%)\end{array}$ & $\begin{array}{c}3 \\
(100 \%)\end{array}$ & $\begin{array}{c}6 \\
(60 \%)\end{array}$ & $\begin{array}{c}12 \\
(44 \%)\end{array}$ & $\begin{array}{c}1 \\
(33 \%)\end{array}$ \\
\hline Compatibility of distributed search & Low & High & High & High & High & High \\
\hline Evidence for compatibility & $\begin{array}{c}\text { Severe } \\
\text { mismatches }\end{array}$ & $\begin{array}{l}\text { No mis- } \\
\text { matches }\end{array}$ & $\begin{array}{l}\text { No mis- } \\
\text { matches }\end{array}$ & $\begin{array}{c}\text { Resolved } \\
\text { mismatches }\end{array}$ & $\begin{array}{l}\text { No mis- } \\
\text { matches }\end{array}$ & $\begin{array}{l}\text { No mis- } \\
\text { matches }\end{array}$ \\
\hline
\end{tabular}

At MediCAL, both vertical and horizontal coordination were loose. On the one hand, this unleashed creativity: lower-level units searched broadly within their domains, contributing strong productivity improvements as well as the lion's share of MEDICAL's strategic projects. On the other hand, severe mismatches emerged among distributed search initiatives; a middle manager explained that "last year's bottom-line financial results could have been much better if innovative developments were better coordinated between the subunits." Particularly, initially promising distributed product initiatives were not adjusted between logistics and production, and the unit head stated that this "mismatch eventually led to the lost profit" in the observed fiscal period. Middle-level and frontline employees blamed other subunits 
for causing the discrepancies. Except for specifying aggregated sales and profitability targets, MEDICAL's top management did not vertically adjust lower-level decisions to achieve overarching goals (e.g., the strategically important production ramp-up). As a result, neither vertical nor horizontal coordination was sufficient to resolve the conflicts among the various distributed actions. A reconciliation of the conflict, however, would have averted the damage and so would have benefitted MEDICAL. Moreover, conflicts among inconsistent process standards across production cells at the frontline level hampered overall performance. In short, a combination of loose vertical coordination and loose horizontal coordination seemed to promote broad distributed search while jeopardizing the compatibility of distributed initiatives.

In FitTINGS and GLASS, both vertical and horizontal coordination were tight. We did find evidence of well-adjusted distributed search, but the impact of that search-in terms of frontline productivity improvements and bottom-up strategic projects related to the manufacturing process — was tightly constrained. A FITTINGS middle manager commented: "The strategic goals are cascaded down meticulously, so that everybody knows what to do in order to meet them. The same goes for the interfaces to the other process areas, which are clearly defined. This gives clear guidance ... everything functions like clockwork, and that does not leave much space for experimentation." Thus, tight vertical and horizontal coordination confined FITTINGS's lower-level search space. At GLASS, where vertical coordination was similarly tight but horizontal coordination was less so, we observed compatible distributed search yet with a slightly greater impact of those activities. In sum, a combination of tight vertical and tight horizontal coordination seems to help search compatibility at the expense of distributed search impact.

The three cases of DRIVES, AUTO, and CONTROLLERS are especially important for our theory building. These manufacturers employed differing combinations of vertical and horizontal coordination. For all three we observed both high impact and compatibility of distributed search. DRIVES emphasized horizontal coordination while refraining from vertical coordination. Horizontal coordination prevented any unresolved mismatches among distributed initiatives; as one manufacturing cell manager stated: "The coordination protocol is so tight that even before championing an initiative we make sure that it is compatible with the neighboring cells, patching up any mismatches." Lower-level managers accounted for 
horizontal interdependencies and "horizontal conflicts typically do not emerge", explained the head of DRIVES. "I told my managers that they are responsible to adjust their actions among themselves."

AUTO also combined loose vertical coordination with tight horizontal coordination and also achieved compatible distributed search with strong impact. Each distributed initiative was required to pass the review of cross-functional steering committees. An AUTO middle manager explained: "Ideas are further refined in the cross-functional steering committee, which meets every week at the functional head level. It makes sure that the process that cuts across the functions will benefit. The ideal is that all distributed initiatives are steered by this process orientation." If incompatibilities become apparent and the functional leaders remain opposed, then "the process leader's task [is] to make a decision. Although the process leader also has a functional hat [being a functional leader at the same time], he has to decide in favor of process requirements and not for his function." It is remarkable that all strategic projects focused on improving AUTO's manufacturing processes have been initiated by middle or frontline management levels, and this phenomenon is indicative of strong distributed search at AUTO.

How did DRIVES and AUTO achieve creative and compatible search? Distributed search initiatives were adjusted to account for horizontal interdependencies, but even so they remained effective and did not end up blocking each other. The cases offer evidence that this result can be explained by loose vertical coordination - under which subunits can independently and thus more flexibly define and interpret their area of search. They can explore configurations that are discoverable only in wider areas of search. Although both of these manufacturers described adherence to the strict horizontal coordination mechanisms as impeding distributed search, simultaneously loose vertical coordination offset this disadvantage by providing sufficient space for distributed search (i.e., via less constrained areas of search). At the same time, horizontal coordination requirements induce decision makers either to champion only so-called win-win initiatives, which improve the performance of all affected subunits, or to adjust initiatives so that they become win-win. As the DRIVES unit manager commented, "I want the plant to form the strategic direction by itself. I do not want to be involved in the content; it should come from the more operational decision makers. But their initiatives have to be looped in the coordination process to improve DRIVES's overall performance ... I care only about the strict adherence to this process." 
Substantiating this outlook was a production cell manager, who stated: "Our senior management gives us freedom to shape and realize our own initiatives, as long as these are well-coordinated through the steering committees. They [top management] even adopted our proposal to change one of our strategic priorities from quality to speed as first priority. This was triggered by one bottom-up initiative that experimented with fast-running production lines." Similarly, AUTO's unit head was convinced that the "big strategic changes are initiated and filled with life by the plant. We want to use that bottom-up creativity. The worst thing would be to suppress it." AUTO's middle managers consistently acknowledged cross-functional strategy workshops as promoting creativity in a way that accounted for interactions: "There, we generated and selected 108 specific projects that included both technology as well as process innovation projects across functions, among which we have already launched five projects for implementation." At both DRIVES and AUTO, loose vertical coordination offered ample flexibility for defining search areas, while the horizontal coordination of distributed search guaranteed compatible aggregation (at the organizational level) of distributed search.

CONTROLLERS was another example of mixed coordination forms, but this organization prioritized vertical over horizontal coordination. Top-down strategic goals served to set the direction for distributed search. We observed compatible distributed search with infrequent (and ultimately resolved) reported conflicts among distributed projects. The unit head of CONTROLLERS acknowledged: "There are sometimes conflicts among the subunits, which I need to resolve when they escalate, making them consistent with our strategic agenda." Thus, CONTROLLERS's tight vertical coordination (with involvement by the top manager) seemed to substitute for the loose horizontal coordination in achieving compatible distributed search. Worth noting is our observation that CONTROLLERS was able to generate strong distributed search contributions. A middle manager of CONTROLLERS described how loose horizontal coordination can expand the search space under tight vertical coordination: "The larger strategic agenda is set by our unit head and then broken down to details for our units. However, we still do act as entrepreneurs. In our areas, we first make quick decisions, and if there are conflicts, we will ultimately be told so by the other areas. If we then still do not find a solution, the problem will be escalated to the unit head who then prioritizes." The impact of CONTROLLERS's distributed search is evident in its dominant 
share of bottom-up strategic projects in the manufacturing process domain and also in its $75 \%$ frontline contribution to productivity improvements.

So here we must ask: How did CONTROLLERS, despite loose horizontal coordination, manage to achieve not only alignment but also compatibility? The answer seems to be that, although the unit head defines goals (and project-level actions) top-down while "making sure that we pursue an overall strategy that is consistent", within those top-down-defined areas the search for improvements can flourish without further horizontal constraints. Here, the CONTROLLERS unit head refrained from imposing too much content detail: "When it comes to manufacturing processes, I only push for change, but I don't impose specific actions." Moreover, since there is loose horizontal coordination, lower-level decision makers can experiment freely without accounting for horizontal interdependencies, thus striving primarily for the improvement of their own subunit's goals. Such search initiatives in subunits may however ultimately benefit the firm as a whole, because they may help overcome the organizational "sticking points" due to horizontal dependencies. In other words, such uncoordinated search may help the organization escape local performance optima and find improved configurations. When the requirement for horizontal adjustment is loose, distributed search can break deadlock situations because the required transitional search steps are not blocked by other (negatively affected) subunits. In fact, the CONTROLLERS unit head welcomed horizontal conflicts because "these smoldering conflicts between subunits also bear potential for innovation. I actually want the units to take their decisions autonomously. They should make decisions."

Thus, CONTROLLERS's loose horizontal coordination seemed to provide space for distributed search, yielding broad and impactful distributed search even in the presence of tight vertical coordination. At the same time, vertical coordination can achieve compatibility via (a) the top-down definition of a strategic portfolio that guides distributed search and (b) the top-down prioritization of strategic projects (when distributed initiatives are at risk to become incompatible). At CONTROLLERS, vertical coordination via prioritization could thus achieve compatibility under loose horizontal coordination-but on an irregular and ad hoc basis: "If these innovations and iterations lead to unresolved problems, I will intervene and prioritize on a case-by-case basis." 


\section{Discussion: Interactions between Vertical and Horizontal Coordination}

\subsection{Interactions and Their Significance}

The foregoing analyses suggest that vertical and horizontal coordination both influence the creativity and, respectively, the compatibility of distributed search, but also that these coordination forms interact to affect distributed search. On the one hand, we have seen how loose vertical coordination leaves distributed search initiatives room to widen their search domains and "stay out of each other's hair" so that they can avoid freezing up when faced with compatibility concerns in the presence of tight horizontal coordination. On the other hand, we have seen how loose horizontal coordination leaves search initiatives the freedom for small autonomous experiments, unhampered by other units' needs, which can yield creativity (enough even to overcome organizational sticking points) within tight top-down alignment. In this way we have seen how vertical and horizontal coordination serve as substitutes: the tightness of either type offers guidance - provided the other type remains loose. Tight vertical coordination guides via alignment with overarching goals, and tight horizontal coordination guides by pushing toward win-win initiatives that benefit more of the organization. Loose vertical coordination enables creativity by granting flexible search areas, and loose horizontal coordination enables creativity by granting local autonomy. Hence we propose that, in acting as substitutes, vertical and horizontal coordination are able to replace each other. Thus tightness is not needed along both coordination dimensions - along one is enough. Indeed, tightness on both coordination dimensions seems to hinder innovations in strategy implementation (as seen in the FITTINGS and GLASS cases). We observe also that looseness on both coordination dimensions fails to provide guidance and results in incompatibilities (as in MEDICAL).

These results are interesting in their own right yet also have important implications for the implementation of operations strategy — especially since the extant operations strategy literature has failed to account for the interactions between vertical and horizontal coordination. Table 1 summarized previous theory and "recommended" combining loose vertical with tight horizontal coordination. Table 7 repeats the structure of Table 1 but while accounting for interactions and with the relevant cases identified. 
Table 7: Interactions between Vertical and Horizontal Coordination

Horizontal Coordination

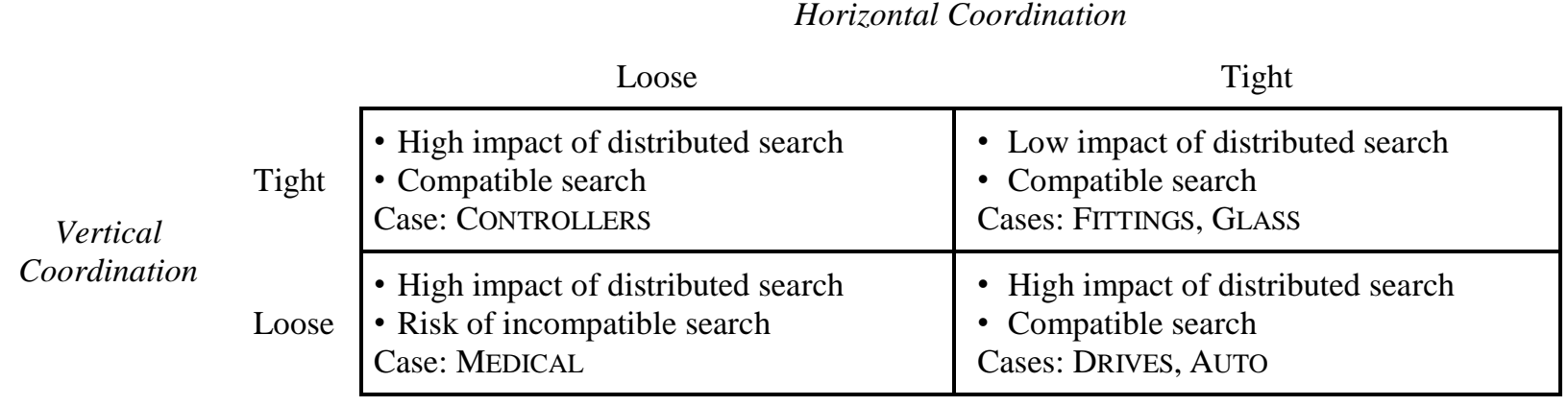

Comparing Tables 1 and 7, we notice first that only one cell differs: the upper left cell of loose horizontal and tight vertical coordination has become attractive in Table 7 as regards its search outcomes (the lower right cell is attractive on those grounds in both tables). This single change is significant, however, because it alters top management's trade-offs. Table 1 emphasizes the trade-off between compatibility and creativity, and only the lower right cell (loose horizontal and tight vertical coordination) is attractive. Table 7 reveals that neither form of coordination can be so tight that it alone shuts down creativity; in other words, leaving either of the two coordination forms loose may enable the organization to be creative and generate improvements. Thus the message of Table 7 differs as compared with Table 1: making one form of coordination tight—while leaving the other form loose — can ensure compatibility while granting the subunits enough search room to make creative improvements. In contrast, tightening both coordination forms may suppress creativity and leaving both of them loose may lead to misalignments.

Upon realizing that compatibility and creativity can be balanced with either vertical or horizontal coordination being tight or loose, we might ask whether we can compare these two combinations on the off-diagonal of Table 7. In other words, which of the two coordination forms should be tightened and which loosened? Our case studies do not allow for ranking the two combinations-CONTROLLERS seems no less successful than AUTO and DRIVES at implementing operations strategy. However, we believe it is more than a lack of data that precludes such a ranking; in particular, the choice of coordination dimensions seems in large part to reflect the "personalities" and leadership styles of the unit head and top management team. The head of AUTO strongly believed in empowerment and creativity in the face of (strategic) uncertainty, and the head of DRIVES strongly believed that he should not make decisions but that his 
workers should. Both leaders implied that it was the responsibility of each team to get along with the others while generating initiatives that yielded more than the sums of their parts. In contrast, the head of CONTROLLERS believed in his own expertise and took the responsibility of steering the unit in a welldefined direction; he felt that workers should be free to innovate while following this direction and that any resulting conflicts with other units would be worked out eventually. In light of these observations, we believe there is a natural connection between findings and leadership. Of course, both that connection to leadership and the predictions of Table 7 need to be tested in further work.

\subsection{Rival Theories: Centralization of Search and Complexity}

The centralization of search, i.e., the extent of decision making by top management, is conceptually related to our research question and especially to our construct of vertical coordination: If the top management team carried out all search activities (and so frontline personnel merely "executed orders"), would the results be the same as when top management guides search by way of detailed goal specifications (i.e., vertical coordination)? Our case studies do indeed suggest that centralization of search coincides with intense vertical coordination (through unit heads with deep domain expertise in CONTROLlERS, FITTINGS, and GLASS), resulting in a more top-down oriented formation of strategic projects (Kim et al. 2014). Therefore, we cannot fully isolate (with this research design) the effects of centralized search from the effects of vertical coordination. However, all the host organizations were too large and complex for full search centralization to be feasible; moreover, centralized search does not negate the viability of distributed search activities. This last claim holds especially for strategic projects that targeted the manufacturing process: in all of the three relevant cases (CONTROLLERS, FITTINGS, and GLASS), we observed manufacturing process-oriented bottom-up strategic projects that followed from successful distributed search. So regardless of the unit's extent of search centralization, there is distributed search, and hence the need for coordination.

We also examined the role of complexity — that is, the number of search dimensions and initiatives and their interdependency links, as represented in Figure 1 (Simon 1962, Levinthal 1997). Complexity could affect the compatibility of search efforts and so could interact with horizontal and vertical 
coordination. Since our case manufacturers operate in different industries with different manufacturing technologies, it is not straightforward to measure and compare complexity in a meaningful way. However, each of this paper's authors independently ranked the cases in terms of complexity (using the definition just given) and obtained consistent results. We find that different levels of complexity neither (a) drive the respective manufacturers' emphases on vertical versus horizontal coordination nor (b) explain how search is affected by such emphasis. As for (a), some of the relatively large and complex manufacturing organizations in the sample emphasize vertical coordination over horizontal coordination (as at GLASS, even though horizontal coordination was also intense) whereas some (e.g., AUTO) emphasize horizontal coordination over vertical coordination. Overall, the specific combinations of vertical and horizontal coordination across our cases seem not to be driven by complexity. With regard to (b), we find no evidence that complexity altered the influence of coordination on the breadth and compatibility of search; that is, the effects operated in the same way.

\section{Conclusion}

Operations strategy scholars have recognized that high performance is not achievable by top-down methods alone: those methods must be complemented by bottom-up, frontline work on implementation. However, bottom-up inputs require coordination to ensure consistency among many parallel actors; hence horizontal coordination is also an important element of search within operations strategy implementation. Previous work has not sufficiently examined whether and how vertical coordination interacts with horizontal coordination during the implementation of operations strategy.

We used detailed case studies of six German manufacturers to identify and characterize interactions between vertical and horizontal coordination in operations strategy implementation. Tight vertical coordination gives frontline personnel detailed guidance, defining search domains to achieve stipulated goals but leaving little room for search. In this context, loose horizontal coordination leaves search initiatives the freedom for small (within the tight top-down guidance) autonomous experiments without regard to the needs of other units. The resulting creativity can even overcome search "sticking points" whereby mutual compatibility constraints practically maintain mediocre solutions. Thus loose 
horizontal coordination can cushion the trade-off between compatibility and creativity that accompanies vertical coordination. In contrast, tight horizontal coordination ensures compatibility of improvement initiatives across organizational units and thus a consistent direction among initiatives in the project portfolio-but again at the cost of reduced creativity because the various simultaneous initiatives must account for their interdependencies. In this context, loose vertical coordination leaves distributed search initiatives room to widen their search domains and "stay out of each other's hair"; hence they can avoid freezing up (because of compatibility concerns) when horizontal coordination is tight. Here loose vertical coordination cushions the compatibility-creativity trade-off posed by horizontal coordination.

We therefore posit that vertical and horizontal coordination can be used as strategic substitutes: the organization can tighten only one of them to derive the benefits of creative organizational search while maintaining its overall direction. If both vertical and horizontal coordination are tight then creativity is throttled and so the organization's improvement performance suffers; if both coordination types are loose, the organization's subunits may no longer follow a common direction and so increase their likelihood of engaging in misaligned and inconsistent actions. These findings extend theoretical knowledge of organizational search. Until now, these subtle interactions between vertical and horizontal coordination and their influence on search have neither been theoretically characterized nor empirically examined. Our theory building departs from the model-based prediction of Rivkin and Siggelkow (2003, p. 305) that vertical and horizontal coordination are strategic complements. The findings reported here also offer useful guidance to managers. Namely, tightening one of the two coordination dimensions can ensure that creativity and compatibility are balanced in operations strategy implementation; tightening both dimensions risks suppressing creativity, and loosening both risks losing direction.

Our cases are large production units that shape their own operations strategies, so they are appropriate choices for the core question we examine. However, all the participating organizations are German. This homogeneity reduces the variance in our observations because problem-solving cultures are likely to differ across countries. Note also that all six organizations have an experienced workforce: employees have a professional education (three years of apprenticeship) and/or have worked in the company for a long time and participated in on-the-job training. Such qualifications may facilitate 
distributed strategic search. It follows that other countrywide and international studies of operations strategy processes are needed before we can fully understand the conditions for effectively implementing operations strategy. And even though the selected cases had stable processes and at least four years of top management tenure, this study is limited by its cross-sectional approach; thus longitudinal studies are needed to assess the temporal stability of our conclusion. Finally, our approach was to build theory—about the interaction of vertical and horizontal coordination-based on six in-depth cases. This means that, absent an accompanying empirical test, our conclusions for operations strategy implementation should be viewed with an appropriate level of skepticism. Nevertheless, we believe that one of this study's conclusions will generalize: Operations strategy implementation involves more than "cascading tools"; it incorporates explicit and implicit means of vertical and horizontal coordination and also should integrate distributed innovation-elements that are seldom explicitly stipulated in process descriptions.

\section{References}

Anderson, E.G Jr, N.R. Joglekar. 2005. A hierarchical product development planning framework. Production and Operations Management 14(3): 344-36

Burgelman, R.A. 1983. Corporate Entrepreneurship and Strategic Management: Insights from a Process Study. Management Science 29(12): 1349-1364

Burgelman, R.A., C.M. Christensen, S.C. Wheelwright. 2008. Integrating technology and strategy: A general management perspective. In: Burgelman, R.A., C.M. Christensen, S.C. Wheelwright (eds.). Strategic management of technology and innovation (5th ed.). Mc Graw Hill: New York

Burgelman, R.A., A.S. Grove. 2007. Let chaos reign, then reign in chaos-repeatedly: Managing strategic dynamics for corporate longevity. Strategic Management Journal 28(10): 965-979.

Cardinal, L. B., Sitkin, S. B., C.P. Long. 2004. Balancing and rebalancing in the creation and evolution of organizational control. Organization Science 15(4): 411-431.

Chandrasekaran, A., K. Linderman, F.J. Sting, M.J. Benner. 2015. Managing R\&D Project Shifts in High-Tech Organizations: A Multi-Method Study. Production and Operations Management (forthcoming).

Chao, R.O., S. Kavadias. 2008. A Theoretical Framework for Managing the NPD Portfolio: When and How to Use Strategic Buckets. Management Science 54(5): 907-921

Cooper, R.G., S.J. Edgett, E.J. Kleinschmidt. 1998. Best practices for managing R\&D portfolios. Research Technology Management 41(4): 20-33.

Cyert, R.M., J.G. March. 1963. A behavioral theory of the firm. Prentice-Hall: Englewood Cliffs, NJ.

De Meyer, A., C.H. Loch. 2008. Technology strategy. In: C.H. Loch, S. Kavadias, S. (eds.). Handbook of New Product Development. Butterworth-Heinemann: Burlington, MA

Eisenhardt, K.M. 1989. Building Theories from Case Study Research. Academy of Management Review 14(4): 532550

Galbraith, J.R. 1974. Organization design: an information processing view. Interfaces 4(3): 28-36 
Gavetti G., J.W. Rivkin. 2007. On the Origin of Strategy: Action and Cognition over Time. Organization Science 18(3): 420-439

Gokpinar, B., Hopp, W. J., S.M. Iravani. 2010. The impact of misalignment of organizational structure and product architecture on quality in complex product development. Management Science, 56(3): 468-484.

Gulati, R., P. Puranam. 2009. Renewal through reorganization: The value of inconsistencies between formal and informal organization. Organization Science, 20(2): 422-440.

Hayes, R. H., S.C. Wheelwright. 1984. Restoring our competitive edge: competing through manufacturing, John Wiley: New York

Hutchison-Krupat, J., S. Kavadias, S. 2014. Strategic Resource Allocation: Top-Down, Bottom-Up, and the Value of Strategic Buckets. Management Science, 61(2): 391-412.

Jick, T.D. 1979. Mixing Qualitative and Quantitative Methods: Triangulation in Action. Administrative Science Quarterly 24(4): 602-611

Kaplan, R. S., D. P. Norton. 1996. The Balanced Scorecard. Boston, MA: Harvard Business School Press.

Kavadias S., R.O. Chao. 2008. Resource allocation and new product development portfolio management. In: C.H. Loch, S. Kavadias, S. (eds.). Handbook of New Product Development. Butterworth-Heinemann: Burlington, MA

Kavadias S, S.C. Sommer. 2009. The Effects of Problem Structure and Team Diversity on Brainstorming Effectiveness. Management Science 55(12): 1899-1913

Kim, Y.H., F.J. Sting, C.H. Loch. 2014. Top-down, bottom-up, or both? Toward an integrative perspective on operations strategy formation. Journal of Operations Management 32(7): 462-474.

Levinthal D.A. 1997. Adaptation on rugged landscapes. Management Science 43(7): 934-950

Loch C.H., S. Kavadias 2002. Dynamic portfolio selection of NPD programs using marginal returns. Management Science 48(10): 1227-1241

Loch, C.H., S. Kavadias. 2011. Implementing Strategy Through Projects. In Morris P., Pinto J. and Soderlund J. (eds.) Oxford Handbook in the Management of Projects. Oxford University Press: Oxford.

Loch, C.H., M. Pich, C. Terwiesch, M. Urbschat. 2001. Selecting R\&D projects at BMW: a case study of adopting mathematical programming models. IEEE Transactions on Engineering Mngmt 48(1): 70-80

Loch, C.H., F.J. Sting, N. Bauer, H. Mauermann. 2010. How BMW Is Defusing the Demographic Time Bomb. Harvard Business Review 88(3): 99-102

Loch, C.H. and S. Tapper. 2002. Implementing a strategy-driven performance measurement system for an applied research group. Journal of Product Innovation Management. 19(3): 185-198.

Loch, C.H., C. Terwiesch. 2008. Coordination and Information Exchange. In: C.H. Loch, S. Kavadias (eds.). Handbook of New Product Development. Butterworth-Heinemann: Burlington, MA

March J.G., H.A. Simon. 1958. Organizations. John Wiley: New York

Marucheck, A., R. Pannesi, C. Anderson. 1990. An exploratory study of the manufacturing strategy process in practice. Journal of Operations Management, 9(1): 101-123.

Mihm J., C.H. Loch, B.A. Huberman, D.M. Wilkinson. 2010. Hierarchical Structure and Search in Complex Organizations. Management Science 56(5): 831-848

Mihm J., C.H. Loch, A. Huchzermeier. 2003. Problem-Solving Oscillations in Complex Engineering Projects. Management Science 49(6): 733-750

Noda T., J.L. Bower. 1996. Strategy Making as Iterated Processes of Resource Allocation. Strategic Management Journal 17(1): 159-192

Rivkin J.W., N. Siggelkow. 2003. Balancing Search and Stability: Interdependencies Among Elements of Organizational Design. Management Science 49(3): 290-311

Rotemberg, J.J., G. Saloner. 2000. Visionaries, Managers, and Strategic Direction. RAND Journal of Economics 
31(4): 693-716

Roussel, P., K.N. Saad, T.J. Erickson. 1991. Third Generation R\&D Managing the Link to Corporate Strategy. Harvard Business School Press: Cambridge, MA

Shane, S.A., K.T. Ulrich. 2004. Technological Innovation, Product Development, and Entrepreneurship in Management Science. Management Science 50(2): 133-144

Siggelkow, N., J.W. Rivkin. 2005. Speed and Search: Designing Organizations for Turbulence and Complexity. Organization Science 16(2): 101-122

Simon H.A. 1962. The Architecture of Complexity. Proceedings of the American Philosophical Society 106(6): 467482

Sting, F.J., J. Mihm, and C.H. Loch. 2011. Collaborative search. Working Paper INSEAD.

Wheelwright, S.C., K.B. Clark. 1992. Revolutionizing New Product Development. Free Press: New York

Yin R.K. 2009. Case Study Research: Design and Methods (4th ed.). Sage: Los Angeles 